\title{
Política, cultura y autopercepción: las identidades en cuestión
}

Michel Agier

Pedro Quintín

\section{Resumen}

La construcción de la identidad "étnica-racial” como proceso social se encuentra atravesado por una amplia gama de factores que permanentemente lo condicionan o lo transforman. En este articulo se pretende realizar un análisis de los factores políticos y culturales que han condicionado la construcción de la identidad de la población negra en las zonas rurales y urbanas tras la aparición de la Constitución de 1991, pero a partir de un ejercicio desconstruccionista de los enfoques esencialistas de la etnicidad. En el articulo se analiza cómo se han dado mecanismos de inclusión política desde arriba, pero con procesos de organización social, a raíz de la aparición de la Ley de negritudes. Esto ha permitido que se ganen espacios de participación política y de adjudicación territorial vía las "comunidades negras", siendo éste un término fabricado por la Ley 70 para denotar a las poblaciones rurales "negras" del Pacífico, que supuestamente pueden demostrar un asentamiento "ancestral". Por otro lado, se analiza la manera cómo ha surgido la identidad negra en centros urbanos y sus áreas de influencia, en el caso de la ciudad de Cali, en la cual se da un sincretismo cultural en el que se mezclan las tradiciones del Pacífico re-inventadas y las dinámicas culturales urbanas. Todo esto en una relación de alteridad negra, en la que juegan representaciones entre individuos negros y no negros. El artículo además realiza una reflexión crítica sobre el papel de la investigación académica sobre los movimientos sociales "étnicos-raciales" y los discursos que se construyen alrededor de este tipo de movilización social. 
Palabras claves: Ley de negritudes (Ley 70), construcción de identidad negra, "comunidades negras", percepción del sí (y del otro), alteridad negra, conciencia identitaria.

\section{Abstract}

Politics, culture and self-perception: the identities in question

The ethnical-racial formation of identity as a social process is came upon several factors which permanently stipulate and transform it. In this article it is intended to analyze the political and cultural factors that have conditioned the identity formation of the black population in the rural and urban zones behind the appearance of the 1991 Colombian Constitution, but through the de-construction of an ethnicity essentialist point of view. In the article, it has been analyzed how an inclusion political mechanism is done by upper groups, but allowing the social organization processes, by reason of the Negritude law. It has allowed to win some ways of political participation and territorial legal appropriation by the "black communities", being this last a word fabricated by the Law 70, to mean the Pacific black rural population that supposedly can show an "ancestral" settlement in the area. On the other hand, it is also analyzed the way that black identity in urban centers has come up and its influence grounds, in the case of Cali city, in which its cultural mix up blends with the reinvented Pacific traditions and urban cultural dynamics. All of this is held in a relation of Negro otherness (alterity), played between black and non-black urban individuals. The article also lays out a critical reflection on the role of academic research about "ethnic-racial" social movements and the ideologies built around this type of social mobilization.

Keywords: Law of Blackness (Law 70), black identity construction, "black communities", perception of the self (and of the other), black otherness (alterity), identity conscience, Cali, Colombia.

\section{Résumé}

Politique, culture et auto perception: les identités en question

La construction de l'identité "ethnique-raciale ", en tant que processus social, est traversée par toute une gamme de facteurs qui la conditionnent et la transforment sans cesse. Dans cet article, nous voulons faire une analyse des facteurs politiques et culturels qui ont conditionné la construction de l'identité de la population noire dans les 
zones urbaines après l'apparition de la Constitution colombienne de 1991, mais à partir d'un exercice de déconstruction des approches essentialistes de l'ethnicité. Nous y étudions comment, en partant du haut, des mécanismes d'inclusion politique ont été mis en place, mais avec des processus d'organisation sociale qui sont à la base de la mise en place de la Loi des négritudes. Cela a permis que l'on gagne des espaces de participation politique et d'adjonction territoriale via les “communautés noires", terme élaboré par la Loi n⿳ํำ 70 , pour désigner les populations rurales "noires" du Pacifique qui ont les moyens de prouver une occupation "ancestrale" des terres. D'un autre côté, nous analysons comment l'identité noire a pu prendre forme dans les centres urbains et dans ses zones d'influence, pour la ville de Cali, où il y a un syncrétisme culturel et où se mêlent les traditions du Pacifique, réinventées avec les mouvements culturels urbains. Tout cela dans une relation d'altérité noire dans laquelle interviennent les représentations entre des individus noirs et non-noirs. De plus, nous avons fait une analyse critique sur le rôle de la recherche académique sur les mouvements sociaux "ethnique-raciaux" et les discours qui se construisent autour de ce type de mobilisation sociale.

Mots-clés: Loi des négritudes (Loi nำ 70 ), construction de l'identité noire, "communautés noires ", perception de soi-même et de l'autre, conscience identitaire, Cali, Colombie. 
¿C uándo y cómo empieza a existir la identidad negra en Colombia y, más específicamente, en la región del suroccidente colombiano? El punto de vista esencialista coloca la identidad como un hecho primero, independiente en sí mismo y causa a su vez de diversos fenómenos sociales y culturales, lo que lo convierte en el principal argumento de los movimientos identitarios. Desde esa perspectiva se asume, implícita o explícitamente, una progresión natural que irradia desde la cultura hacia la identidad, y desde la identidad hacia la política. Al tratar de recorrer el camino en sentido inverso (desde la política a la identidad, y desde ésta a la cultura), nosotros queremos "deconstruir" ese proceso analíticamente. Por lo tanto, no se pretende aquí deslegitimar los movimientos sociales que lo gestan y usan dentro de un proceso de lucha por los derechos sociales y políticos a través de la diferencia cultural, sino simplemente mostrar explícitamente los entrecruces y los mecanismos complejos que están en la base de esta afirmación identitaria. En el centro de todo ello, se encuentra el debate sobre la identidad cultural. ${ }^{1}$

\section{Política}

La invisibilidad política y cultural de las poblaciones negras, que es una de las formas de su inclusión marginal desde el punto de vista social y económico dentro de la nación colombiana (Friedemann, 1993; Wade, 1993), duró aproximadamente hasta finales de los años sesenta. En esos momentos, junto con algunos tímidos movimientos políticos contra la discriminación racial (por ejemplo, el movimiento Cimarrón), tuvo lugar el inicio - precedido ciertamente por unos pocos estudios de corte folklórico- de las investigaciones de las ciencias sociales sobre la población afrocolombiana. Dos grandes corrientes de interpretación se hicieron dominantes: por un lado, se pusieron de evidencia las "estrategias adaptativas" (Whitten, 1986 [1974]) desarrolladas por las poblaciones negras dentro del Nuevo Mundo; por otro, se resaltaron las "hue- 
llas de africanía" (Friedemann y Arocha, 1986) que sobrevirían funcional y expresivamente entre estas poblaciones en el desarrollo de su vida americana. Estas dos interpretaciones reproducían, para el caso del Pacífico colombiano, los grandes modelos teóricos de la antropología de los años cuarenta, cincuenta y sesenta: el de las estrategias adaptativas y de los sincretismos nacidos del "encuentro" de los Africanos con los Europeos en el Nuevo Mundo (Herskovits, 1941), y el que supone la idea del "corte" entre los mundos africanos y americano, y el respectivo mantenimiento de "culturas en conserva" en el Nuevo Mundo (Verger, 1957; Bastide, 1967).

En Colombia, el descubrimiento y reconocimiento de los aportes afro-americanos a la cultura nacional se hizo, en los años cincuenta, a partir de cierta valorización positiva de la Costa del Caribe, inspirada a su vez por el éxito de las músicas y danzas negro-americanas y cubanas. ${ }^{2}$ Por su parte, los habitantes negros de la Costa Pacífica permanecieron aún largamente olvidados y marginados, dentro de un orden racial en que la diferenciación regional se erigía en elemento jerarquizador a la hora de valorar o no a ciertas poblaciones: las de la Costa Pacífica se ubicaban, de alguna manera, en uno de los peldaños más bajos. Esta posición se relacionaría con su consideración como reductos empobrecidos, excrecencias de la sociedad mayor, antes que como espacios relativamente autónomos, con ciertas peculiaridades y diferencias culturales y sociales ${ }^{3}$. Así, por ejemplo, los varios siglos de represión, persecución y diabolización de las creencias, de los rituales y de las ceremonias de origen africano o amerindio por los representantes de la Iglesia Católica, española, primero, y republicana, después, habrían descompuesto sus formas culturales y habrían favorecido su disolución en los cultos a los santos católicos (con diferentes versiones de Cristo y de María, de San Antonio, etc.), así como en la aparición de santos, vírgenes y de figuras e imágenes selváticas de origen hispánico, indígena o africano (las visiones del duende, de la tunda, de la madredagua, etc.), e incluso en los ritos derivados de las celebraciones católicas; por ejemplo, en los funerales y velorios (Losonczy, 1997; Vanín, 1999; Agier, 2001). Esta fuerte inclusión paradójica ${ }^{4}$ explica la inexpresión -que Nina S. de Friedemann ha llamado "invisibilidad"- de la identidad afrocolombiana: las creencias y rituales, de alguna forma mezclados (afro-indígena-hispánicos), se desarrollaron bajo el molde estructural católico impuesto por la colonización española en tiempos de la Inquisición -pero con continuidad republicana-, y crearon las 
condiciones para que se diera un "mestizaje" tanto desigual como original (Borja Gómez, 1998; Gruzinski, 1999; Mintz y Price, 1976-1992).

Es a partir de las políticas desarrollistas aplicadas a la región, así como de una revalorización, a escala mundial (y retomada localmente por las organizaciones no gubernamentales y por la misma Iglesia Católica y por el Estado), de los discursos que reivindican el regionalismo, el localismo, la identidad étnica y la protección del medio ambiente, que la identidad afrocolombiana del $\mathrm{Pa}-$ cífico comienza a surgir de forma fuerte en los escenarios políticos, aproximadamente a fines de los años ochentas e inicios de los noventas. La Constitución del año 1991 trata de favorecer las nuevas movilizaciones de la "sociedad civil" con el objeto de hacer frente a un contexto de incremento de la violencia y de reconocida pérdida de la legitimidad del Estado. El período 1991-1993 estuvo marcado por una movilización importante de los espacios y medios intelectuales y políticos negros y de los espacios académicos, desembocando en la implementación de la Ley 70 de 1993 y en los decretos de su aplicación de 1995 (Agier y Hoffmann, 1999).

Esta situación permitió la formación política de un nuevo movimiento negro (denominado PCN "proceso de comunidades negras"), que desarrolla un discurso de carácter "étnico territorial”; es decir de valorización de los particularismos culturales, educativos, laborales, territoriales de las poblaciones negras-afrocolombianas, perdiendo fuerza de manera explícita la estrategia de lucha antiracista y de integración igualitaria a la sociedad, que había liderado el movimiento Cimarrón en los años setenta y ochenta. De esta manera el PCN asegura un vínculo estrecho con la legitimidad institucional dada por la Ley 70. Pero esta dinámica fue mediatizada y cooptada inmediatamente por el Partido Liberal, que ha controlado históricamente el juego clientelista dentro de la región $\mathrm{Pa}$ cífica. Ello, pese a los cambios en el período más reciente en los que se ha dado un acercamiento, relativo y tímido, entre los movimientos sociales en general y la política electoral. ${ }^{5}$

Sin embargo, es necesario tener en cuenta que son significativos el poder simbólico de la Ley 70 y sus correlatos institucionales y legales en las dinámicas sociales y políticas de finales de los años noventa. Ellos colocan en una situación nueva a las poblaciones afro-colombianas al dotarlas, quizás por primera vez en su historia, de argumentos ya legitimados (precisamente por provenir del mismo Estado) a partir de los cuales sus reclamos deben ser escuchados y evaluados. Los niveles en que esos reclamos y movi- 
mientos sociales son capaces de articularse a nivel local y regional, las idas y venidas, contradicciones y acuerdos que suscitan, los retrocesos y avances a que ellos llevan son, de todas formas, aspectos que ameritan nuevas y más profundas investigaciones: la posibilidad de reconocer tendencias o impactos más generales pasa por una comprensión de los procesos locales y micro-regionales. De momento, puede destacarse que en las formas y lógicas de esos procesos, y ciertamente mano a mano con los líderes locales, la presencia de elementos externos sigue siendo fundamental a la hora de otorgarles continuidad y coherencia ${ }^{6}$. También, que las luchas internas no sólo se dan al nivel de las bases sociales (entre campesinos, pequeños propietarios, comerciantes, etc.) sino incluso entre las instituciones y organizaciones que, más directamente vinculadas en su origen al desarrollo y generalización de la Ley 70 y dependientes de su reconocimiento por parte del Estado y/o de los organismos privados que trabajan con estas poblaciones, quieren convertirse en los representantes privilegiados o intermediarios exclusivos de las comunidades locales hacia el exterior. ${ }^{7}$ Igualmente, por último, que las continuidades y las rupturas en los procesos de la política formal de la región del Pacífico han sido producidas tanto por dinámicas de nivel local y regional como, y quizás en algunos casos de forma mucho más significativa y definitiva, por el discurso y las prácticas asociadas a la implementación de la Ley 70: a la necesidad de adaptaciones de los discursos, de nuevas estrategias y de tomas de posición ante la ley, se han debido sumar las luchas y conflictos de interés con nuevos movimientos sociales, asociaciones y agrupaciones políticas surgidas al amparo de ella. ${ }^{8}$

De esta forma, la Ley 70 estimula una situación de desarrollo de movimientos identitarios jamás vista hasta entonces, dado que el acceso a los recursos reposará, sobre todo, en la producción de una identidad cultural y sobre una nueva relación entre identidad y territorio: en el año 1993, las poblaciones negras del Pacífico colombiano devienen legalmente un "grupo étnico" gracias al agrupamiento, retórico en el texto mismo de la ley, entre las nociones de "comunidades negras" y de "regiones rurales del Pacífico". La identidad existe (y es pensada), en tal sentido, sobre el modelo "étnico" de los indígenas (andinos) de los resguardos, y se centra principalmente en la cuestión de la propiedad de las tierras, con conflictos y relaciones de fuerzas políticas creadas alrededor de las instituciones y los créditos del desarrollo regional. Ella es, al contrario, más ambigua, invisible u opcional a partir del momento en que uno la aborda desde los aspectos existenciales e individuales 
(ver más abajo). De tal forma que si la titularización de tierras y, con ella, la identidad negra, no son colectivas y "étnicas" (en un sentido holista, donde el todo debe remitir a las partes, el colectivo prima sobre el individuo), el conjunto del edificio jurídico y propietario pierde su sentido y resulta inaplicable (ver Agier y Hoffmann, 1999).

\section{Percepción de Sí (y del Otro)}

Las auto-identificaciones muestran el carácter relativo, relacional y situacional de la identidad. Ante todo, la identidad tiene carácter relativo en la medida en que ella depende estrechamente del contexto. Por ejemplo, la respuesta a la pregunta del Censo Nacional de Población de 1993, que hacía referencia a la pertenencia de los encuestados a algún grupo étnico, arrojó muy bajas respuestas positivas a nivel nacional. No obstante, las declaraciones de pertenencia a "una etnia, un grupo indígena o a una comunidad negra" fueron más numerosas en la región del Pacifico, y llegan a ser ampliamente mayoritarios entre los sectores donde existía, al momento del Censo, una movilización identitaria más fuerte para la realización y aplicación de la Ley 70 y la titulación colectiva de tierras ${ }^{9}$. También la identificación es un fenómeno relacional. Ella se construye en una relación cara a cara, en una interacción entre dos o más actores. Este escenario es una situación de miradas cruzadas, donde cada uno actúa en función de anticipaciones y de presupuestos sobre lo que puede ser la mirada del otro, por ejemplo en el caso de la relación entre encuestador y encuestado en estudios cuantitativos. Y, finalmente, ¿ estamos en presencia de identidades opcionales o situacionales? Hay una tendencia a la indefinición, es decir, a una voluntad de neutralizar las características raciales, que es perceptible principalmente en la identificación opcional de "trigueño". De ahí surge la idea de una cierta libertad de opciones identitarias en un país mestizo (como se puede ver por el número de ítems en respuesta a la pregunta del color de la piel en la encuesta Cidse/Ird). De hecho, la difusión del estigma racial en el conjunto de la sociedad, y entre las poblaciones negras, sugiere que hay una serie de ajustes ante cada situación, más que unas "elecciones" identitarias realizadas a priori y/o para siempre. Por ejemplo, en Puerto Tejada (Norte del Cauca), la vieja generación de pobladores negros rechaza a los "negros" procedentes del Pacífico Sur que han migrado al pueblo en épocas recientes con los mismos argu- 
mentos sociales con que los blancos en otra época rechazaron a sus padres (Hurtado, 1999).

La realidad dominante pareciera ser, en definitiva, la de un racismo difuso y poroso, como dispositivo discriminador no homogéneo y no necesariamente dicotómico, con matices y variaciones que permiten la representación en gradaciones de "colores de piel", dependiendo de contextos específicos, urbanos y regionales. No obstante, ¿qué cambio han introducido los recientes movimientos identitarios a partir de la retórica afrocolombiana en las representaciones de la identidad de las poblaciones negras de Colombia y en sus condiciones sociales?, ¿Cuál ha sido su incidencia sobre los estereotipos racistas y sobre las respuestas desde sectores de la población afrocolombiana a la discriminación racial? Estas preguntas quedan abiertas para ser estudiadas tanto en las poblaciones afrocolombianas como en las no afrocolombianas.

\section{Cultura}

Hoy, la identidad cultural se configura como una construcción social de múltiples facetas. En síntesis, consideramos que esas facetas son las siguientes:

- Inversiones de capitalistas y profesionales que hacen de la cultura una "mercancía". Sobre ella se efectúan toda una serie de trabajos y actividades, tanto al nivel de la producción y de la distribución como del consumo. Un trabajo que supone especializaciones, disponibilidad de tiempo, movilidades y desplazamientos espaciales, relaciones, vínculos y negociaciones con financiadores o "sponsors" (el municipio, las diferentes oficinas del Estado, las ONGs, agentes privados). De este modo la cultura aparece entonces como una "mercancía" en tanto que objeto transformado por el capital y por el trabajo en él invertidos, más que un objeto ya hecho y acabado (Wade, 1999), y además como un "recurso" maleable, susceptible de múltiples usos, sean ellos políticos, económicos o ideológicos.

- El trabajo de la memoria. Las movilizaciones identitarias de carácter étnico han dado a la rememoración de los lugares y del pasado un papel central dentro del discurso de legitimación, y simultáneamente de diferenciación de las poblaciones negras, a escala tanto individual como local y urbana-rural. El trabajo realizado sobre la memoria, que -co- 
mo sucede con la cultura- puede pragmáticamente ser también político, económico o ideológico, pone en movimiento, actualizándolas, las relaciones interétnicas existentes hasta entonces entre negros, blancos, mestizos e indígenas. Las investigaciones, las censuras, las selecciones efectuadas, así como la inversión de la relación entre ancianos y jóvenes en el control de los saberes colectivos, constituyen progresivamente aquello que uno podría definir como una recreación de la memoria en un contexto localizado repleto de tensiones e incluso de conflictos (Hoffmann, 2000; Quintín, 2000).

- El trabajo simbólico que se desarrolla en las innovaciones culturales. La puesta en relación de las estrategias identitarias y de las actuaciones artísticas y rituales, es decir, la ritualización de las identidades, coloca en escena figuras simbólicas que permiten crear los momentos de reconocimiento colectivo, más o menos efímero, dentro de los contextos de ceremonias, fiestas, carnavales, etc. Dentro de aquellas situaciones fuera de lo ordinario, el reencuentro entre los individuos y una historia o un destino común, es simbolizado por algunas figuras o entidades reconocibles, de origen local o híbrido. Estas formas simbólicas permiten crear un sentimiento de identidad, y se multiplican desde el momento en que se deja libre curso a la imaginación. Ellas integran entonces una panoplia de símbolos identitarios étnico-regionales en los que su engranaje y su articulación está a veces aún pendiente de ser realizada (Agier, 1999a, 2001a). Ciertas figuras, las visiones en particular (tunda, madredagua), ciertos objetos (marimba, tambores) o ciertas ceremonias y danzas (currulao, chigualo, arrullo) empiezan, en los contextos urbanos, una nueva vida en tanto que símbolos identitarios, al tiempo que ellos desaparecen de las orillas de los ríos, empujados por los ritmos del trabajo, los desplazamientos forzados, por la reducción del espacio público a causa de un clima de terror cada vez más generalizado en la región, o por la competencia de la radio, el tocacintas o los canales de televisión, cuyo uso que se generaliza en las tardes gracias a las plantas generadoras de energía eléctrica.

- La producción de "imágenes" sobre la cultura del Pacífico. Gestadas tanto por parte de sus mismos residentes, como por gentes de afuera (negros y no negros) y, también en 
ocasiones, por la academia misma, las representaciones e ilustraciones, de la cultura del Pacífico tienden a reproducir una imagen holista de los lugares de origen (la communitas idealizada) que se opone a otra imagen, individualizada y por tanto menos amable, de los lugares urbanizados a donde llegan a vivir estas poblaciones. Aquí, los lazos sociales (y de identidad) se diluirían, tenderían hacia lo "nada”, o hacia el sueño utópico y el fin apocalíptico. El recurso a fotografías para reconstruir el pasado familiar, la filiación genealógica, así ella sea exclusivamente imaginaria (dado que cada vez hay menos o más efímeros retornos a los lugares de origen), participan de una cierta "ficcionalización" de las representaciones de la identidad negra del Pacífico (Quintín, 1999a, 1999b, 2000; Vanín, 1999).

La producción de identidad en el litoral Pacífico se sitúa, principalmente, dentro de esferas sociales e imaginarias alejadas del mundo al que parecía referirse en un principio -el litoral Pacífico- y, por lo tanto, de una perspectiva que asociaba históricamente la identidad "racial" y la regional. Ahora entran en juego los nuevos discursos identitarios vía eventos modernos que congregan a los especialistas de las culturas locales, por ejemplo, alrededor de la marimba o del carnaval en Tumaco, o la chirimía y las fiestas de San Pacho en Quibdó. Por el lado de las grandes ciudades del litoral (Tumaco, Buenaventura, Quibdó) y más aún de la ciudad de Cali -y el Distrito de Aguablanca-, se producen procesos de producción de "culturas negras", no como simple difusión de prácticas culturales desde lo "rural" sino de modo más bien propio, urbano, y además en el contexto de una modernidad globalizada. Las ciudades son los lugares receptores de múltiples y heterogéneas imágenes e informaciones a partir de las que se crean las referencias identitarias que permiten pensar la identidad negra, en primer lugar desde la modernidad urbana. La marimba y el baile del currulao y de chirimía, los cultos del catolicismo popular, las visiones de los ríos y de los bosques siguen una trayectoria de desplazamiento y transformación que las llevan de las orillas de los ríos hacia la ciudad de Tumaco y su pequeño carnaval, hacia las prácticas cotidianas de los pobladores populares de Buenaventura y, más allá aún, hasta la pobladísima ciudad de Cali (con más de dos millones de habitantes) con su Festival de Música del Pacífico Petronio Álvarez, el cual lleva ya cinco años, por una parte, y sus grupos barriales por otro lado. Se trata de una migración de los espíritus que replica la migración de las gentes del Pacífico. 
Pero en todo ese proceso, otras imágenes son reencontradas y se mezclan con las primeras: el "mestizaje" resultante comienza ya desde la misma ciudad de Tumaco, donde son muy perceptibles las presencias e influencias ideológicas de actores "globales" (Plan Padrinos, Iglesia Católica, el mismo Estado - por vía de su sistema educativo, sanitario, judicial, represivo o administrativo-, y hasta de agentes externos vinculados al capital internacional -empresas agro-industriales, narcotráfico-), así como de las informaciones e imágenes mass-mediáticas (radio, prensa, televisión): la política nacional e internacional, los héroes de Disneylandia, las estrellas de la música popular, del cine, la televisión y de los deportes, los orishas (que vienen de Cuba o de Miami), entre otras muchas, constituyen las imágenes que son transmitidas por esos canales y que se suman a las creencias, saberes e imágenes previas, ellas mismas resultados de otras mezclas más antiguas. Estas múltiples influencias se encuentran, por ejemplo, en el carnaval de Tumaco, cruzándose o mezclándose (Agier, 2001a). En Cali, las composiciones de música rap de los grupos de jóvenes del Distrito de Aguablanca incorporan y transforman las historias y leyendas que circulan por el barrio y que provienen, en parte, de un registro más antiguo traído desde las regiones de origen (es el caso de las visiones persistentes hasta hoy en las áreas rurales del Pacífico); pero lo cierto es que esta cultura hecha en la ciudad recibe e interpreta igualmente los estilos y emblemas de la cultura negra juvenil de procedencia estadounidense diseminada mundialmente por los canales de consumo cultural masivo -aunque también por la vía de circuitos de nivel personal y familiar. En la actualidad existen más de 500 grupos de rap en esta zona de la ciudad y por lo menos 30 a 40 de breakdance. Esto permite explicar por qué los grupos de rap constituyen la expresión cultural más importante de denuncia de segregación o exclusión social de la gente joven de la franja oriental y de ladera de Cali, con fuerte dosis de afirmación de autoestima, muchas de ellas a través de contenidos agresivos de sus líricas contra el racismo, la violencia, los estereotipos raciales y de pobreza que marcan estas regiones. Hoy en día es un movimiento en expansión, que cuenta poco a poco con circulación en CDs de algunos grupos, llevando su influencia incluso a sectores de clases medias bajas y medias de población afrocolombiana, pero también a amplios sectores de jóvenes mestizos y "blancos". Otros fenómenos de producción cultural entre las poblaciones afrocolombianas de Cali, en el contexto de invención de referentes "comunitarios" al mismo tiempo constituyen una alternativa económica: el desa- 
rrollo en los últimos cinco años de peluquerías masculinas "afro" 10 en todos los barrios del Distrito de Aguablanca y en otras áreas de la ciudad, en forma de pequeños negocios entre jóvenes hombres negros-mulatos para la generación de ingresos. Las peluquerías "afro" hoy en día son lugares de circulación de información cultural sobre música, bailes, rumbas, actividades deportivas y oportunidades laborales entre los jóvenes de los sectores populares del Distrito de Aguablanca y otras zonas de la ciudad con clientes hombres negros-mulatos y ya en muchos casos también mestizos.

De todas estas mezclas nace la posibilidad de una historia del hip-hop en el Distrito de Aguablanca, en la que el contexto de referencia es aquél de la marginalización social y económica, de la segmentación espacial urbana, de la discriminación socio-racial vivida en la ciudad como en el trabajo, y de la búsqueda, individual y colectiva, de una respuesta a esta situación: la auto designación como "ghetto" (término tomado prestado de la imagen del ghetto negro norte-americano, pero en una acepción que articula y solapa elementos raciales y de clase, véase Urrea, 2000:22) participa de esta búsqueda de una comunidad imaginada que se forma alrededor de un estigma vivido localmente. Al final, como lo resalta Urrea (2000:28), los jóvenes y niños del Distrito de Aguablanca, en Cali, pueden moverse en los dos registros culturales, de música "tradicional" del Pacífico y las variantes diversas del hip-hop, al igual que gozar de la música salsa para efectos del encuentro de parejas o de conquista amorosa. No se presentan oposiciones. Podría decirse que cada registro juega un papel según los contextos y dimensiones de la vida de los jóvenes: a través del hip-hop, sobre todo del rap, para la autoafirmación y denuncia social, de las danzas tradicionales para la continuidad de experiencias de comunidad cultural inventada procedente de diversas regiones del Pacífico, y de la salsa para el juego erótico-amoroso.

\section{La conciencia identitaria, ¿para qué? El papel de los intelectuales, el rol de los investigadores}

Desde su inicio, el proyecto CIDSE/IRD ha asociado, en tanto ello ha sido posible, a diferentes actores que estaban directamente concernidos por la propuesta de investigación tanto en su desarrollo como en sus resultados. Los talleres iniciales organizados por el "Laboratorio de Culturas Negras" de la Universidad del Valle durante el segundo semestre de 1995, el proceso de aplica- 
ción del cuestionario de la encuesta cuantitativa Cidse-Ird-Colciencias ("Encuesta de movilidad, urbanización e identidades de las poblaciones afrocolombianas"); las sucesivas presentaciones de resultados en Tumaco (al grupo Palenque, al sector cultural de la ciudad y a los Consejos Comunitarios de varias veredas) y en Cali (el Seminario Internacional del proyecto Cidse-Ird-Colciencias, "Identidades y Movilidades en el Pacífico colombiano", llevado a cabo en noviembre de 1998; y la presentación de resultados de la encuesta Cidse-Ird-Colciencias en los barrios El Retiro y Charco Azul en febrero de 1999): en todos estos casos, algunos intelectuales y líderes implicados en las situaciones estudiadas (y así mismo haciendo parte del "objeto") han sido asociados, a diferentes niveles y de formas distintas, a la propia investigación.

Con ello, el equipo del proyecto ha podido constatar la difícil relación entre las encrucijadas del saber y las encrucijadas de la identidad. Por ejemplo, en el análisis crítico de la Ley 70, que ha puesto en debate la correlación entre la identidad "negra" y la posibilidad de pensar en una identidad (o cultura) particular y específica del Pacífico. La idea de una cultura de los lugares (en el sentido de una serie de situaciones presentadas y observables en un marco concreto) permite a los investigadores des-substancializar la relación entre identidad y cultura, en particular en su versión aparentemente más naturalizante, aquélla de una verdad biológica que asociaría la "identidad racial" (ciertas apariencias físicas y características fenotípicas) a ciertas competencias culturales "africanas" heredadas. La relación entre identidad y cultura no es automática, única, dada, definitiva, sino, al contrario, problemática. Sin embargo, incluso esta idea es insuficiente, dado que ella puede, a su vez, establecer o validar la idea de "territorio" como a priori, cuando también es una fabricación provisional, transformable y un cruce constante de las sucesivas luchas existentes. Por lo tanto, la correlación entre cultura y lugar debe ser también reexaminada. El debilitamiento de las fronteras (sociales y culturales), gracias a los nuevos medios de comunicación y de transporte vuelve caduca la idea que un lugar materialmente delimitado pueda ser la referencia identitaria única, o principal, de un individuo o de un colectivo.

Pero, a su vez, es claro que este debate teórico se encuentra constantemente "perturbado" por las tensiones locales. Así, afirmar la "identidad territorial" contra la "identidad racial" termina por dar argumentos a aquellos agentes que predican una titulación 
de tierras para todos los que viven y están en ella: ya sea con el argumento de la ancestralidad, el de los derechos de los primeros llegados (los "nativos"), se produce olvido y/o desconocimiento de los procesos históricos -no siempre pacíficos- de expulsión y expoliación de tierras, etc. Al final de la reflexión, no podemos dejar de ser conscientes del papel que juegan estos diferentes argumentos dentro de las posturas políticas, económicas y sociales que, entre unos y otros, se tejen dentro y sobre la zona pacífica y de las que no podemos ser ajenos. ¿Debemos, por lo tanto, dar (así sean falsos) argumentos a aquéllos cuya postura política y lucha nos parece más legítima? Seguramente hoy los campesinos negros "agrupados en comunidades", junto a los grupos indígenas, son los más desamparados y los más frágiles de la región (Agier, 1999b; Hoffmann y Quintín, 1999).

Sin duda, nos hace falta ir más allá de la deconstrucción para poner en relación de manera más sistemática la cultura, la identidad y la situación (más que el espacio). Estamos en medio de una situación de desarrollo (que falta caracterizar más finamente, pero cuyo elemento principal es la introducción de un "maná" financiero y de formas exteriores de acceso a los recursos) que condicionan los conflictos de identidad y los cambios culturales micro y macro-regionales.

¿Aún se puede dialogar con argumentos exclusivamente objetivos, "científicos" (sin que se dé un exceso de malentendidos) con unos agentes estrechamente implicados en esa situación y directamente afectados por ella? ¿Cuáles pueden ser los términos de ese diálogo? Se trata de preguntas cuyas respuestas ni son fáciles ni pueden ser dadas en abstracto. De una manera más pragmática, la formación, a lo largo de la investigación, de encuestadores y de investigadores "locales" y "comunitarios" es uno de los hechos y logros más evidentes del proyecto, en tanto que ellos se constituyeron no sólo en un medio básico de la investigación sino hasta en co-partícipes muy activos de la misma. Quizás sea este uno de los resultados más pertinentes ya que ha permitido reintroducir constantemente la complejidad en las visiones más simplificadoras y dualistas que se enfrentaban en el terreno.

\section{Notas}

1. Para una aproximación general de esta cuestión, a partir de material empírico de Colombia y Brasil, véase Agier (2001b). 
2. En su artículo del presente número, Wade retoma el tema. Ver también, Gilard (2000), Wade (1993).

3. Véase al respecto el articulo de O. Hoffmann en este mismo volumen.

4. Paradójica a la luz de la marginalización económica y de la exclusión política.

5. Ver las reflexiones acerca de los nuevos movimientos sociales afrocolombianos de Escobar (1999). Ver también Agudelo (1999a, 1999b) e Hoffmann (1999).

6. Ver el caso de la ACAPA (río Patía, zona rural de Tumaco) con la asesoría directa de la Iglesia Católica (Rivas, 2000).

7. Ver Hurtado (2000) para la zona del Norte del Cauca, desde una perspectiva histórica pero haciendo énfasis especial en los procesos más recientes relacionados con la fase post-Ley 70 .

8. Sobre este último punto, para un estudio de los cambios y continuidades en los comportamientos electorales, en perspectiva histórica y comparativa de las diferentes dinámicas regionales dentro de la Costa Pacífica, véase Agudelo (2000).

9. Al respecto consúltese el artículo de O. Barbary, H. F. Ramírez y F. Urrea en el presente volumen.

10. En las que tanto los cortes de cabello que se realizan, la música que se escucha y la decoración del ambiente (saturada de afiches de líderes políticos, músicos y deportistas negros) remiten a identificaciones con la población negra.

\section{Bibliografía}

AGIER, Michel y HOFFMANN, Odile (1999). "Les terres des communautés noires dans le Pacifique colombien. Interprétations de la loi et stratégies d'acteurs". Problèmes d'Amérique Latine, $\mathrm{n}^{\circ} 32$, jan/mar, pp.17-42 (en español en la revista Territorios, Bogotá).

AGIER, Michel. (1999a). "Tres estudios sobre la cultura del Pacífico colombiano". In VV.AA., Imágenes de las "culturas negras" del Pacífico colombiano. Documento de Trabajo, nำ 40, CIDSE-IRD, Universidad del Valle, Cali, pp.15-26.

AGIER, Michel. (1999b). "Etnología y compromiso". In J. Camacho \& E. Restrepo (eds.), De montes, ríos y ciudades. Territorios e identidades de la gente negra en Colombia. Bogotá, Natura/Ecofondo/Ican, pp. 335-349.

AGIER, Michel (2001a). "Le temps des cultures identitaires. Enquête sur le retour du diable à Tumaco (Pacifique colombien)”. L'Homme, nº 157, pp. 87-114.

AGIER, Michel (2001b). "Distúrbios identitários em tempos de globalização". Mana, vol. $7, \mathrm{n}^{\circ} 2$, pp. 7-33.

AGUDELO, Carlos (1999a). "Colombie: changement constitutionnel et organisation des mouvements noirs”. Problèmes d'Amérique Latine, nº 32, jan./mar, pp.43-52.

AGUDELO, Carlos (1999b). "Política y organización de poblaciones negras en Colombia”. In VV. AA., Hacer politica en el Pacífico Sur: algunas reflexiones. Documento de Trabajo nํㅜㅇ, Cidse-Ird, Universidad del Valle, Cali, pp. 3-36.

AGUDELO, Carlos (2000). "Comportamiento electoral en poblaciones negras. Algunos elementos de análisis". In VV.AA., Impactos de la Ley 70 y dinámicas políticas locales de las poblaciones afrocolombianas: Estudios de caso. Documento de Trabajo No. 50, Cidse-Ird, Universidad del Valle, Cali, pp.29-104. 
BASTIDE, Roger (1967). Les Amériques noires. Paris, Payot.

BORJA GOMEZ, J. H. (1998). Rostros y rastros del demonio en la Nueva Granada. Bogotá, Ariel.

ESCOBAR, Arturo (1999). El final del salvaje. Naturaleza, cultura y politica en la antropología contemporánea. Bogotá, ICAN/CEREC.

FRIEDEMANN, Nina S. de. (1993). La saga del negro: Presencia africana en Colombia. Bogotá, Instituto de Genética Humana, Pontificia Universidad Javeriana.

FRIEDEMANN, Nina S. de y AROCHA, Jaime. (1986). De sol a sol: Génesis, transformación y presencia de los negros en Colombia. Bogotá, Planeta Editorial Colombiana.

GILARD, J. (2000). "Scandale noir en pays métis: la Colombie et les danses Négro-Américaines (1940-1950)”. In E. Apprill (org.), Danses latines et identités. Paris, L'Harmattan, pp.33-45.

GRUZINSKI, Serge (1999). La pensée métisse. Fayard, Paris.

HERSKOVITS, M. J. (1941). Myth of the Negro past. Boston, Beacon Press.

HOFFMANN, Odile (1999). "Identidades locales, identidades negras: la conformación del campo político en Tumaco (1950-1998)”. In VV.AA, Tumaco: haciendo ciudad. Historia, cultura e identidad. Ican/Ird/Universidad del Valle/Colciencias, Bogotá, pp. $245-276$.

HOFFMANN, Odile (2000). "La movilización identitaria y el recurso de la memoria (Nariño, Pacífico Colombiano)”. In C. Gnecco y M. Zambrano (eds.), Memorias hegemónicas, memorias disidentes. ICANH-Universidad del Cauca, pp. 97-120.

HOFFMANN, Odile y QUINTÍN, Pedro (1999). “Organización social, dinámicas culturales e identidades de las poblaciones afrocolombianas del Pacífico y Suroccidente en un contexto de movilidad y urbanización”. Boletín Socioeconómico nำ 31 , CIDSE, Universidad del Valle, Cali, pp. 134-140.

HURTADO, Teodora (1999). "Siervos sin tierra: poblaciones de migrantes en Puerto Tejada, entre el estigma, la incertidumbre y la aceptación”. In VV.AA., Imágenes de las "culturas negras" del Pacífico colombiano. Documento de Trabajo nำ, Cidse-Ird, Universidad del Valle, Cali, pp.27-43.

HURTADO, Teodora (2000). “Treinta años de protesta social: El surgimiento de la movilización étnica afrocolombiana en el Norte del Cauca”. Documento de Trabajo No. 50, CIDSE-IRD, Universidad del Valle, Cali, pp.105-138.

LOSONZCY, Anne-Marie (1997). Les saints et la forêt. Rituel, société et figures de l'échange avec les indiens emberá chez les Négro-Colombiens du Chocó. Paris, L'Harmattan, 419p.

MINTZ, Sydney y PRICE, Richard (1992 [1976]). The birth of the African-American culture. Boston, Beacon Press.

QUINTÍN, Pedro (1999a). "Memorias y relatos de lugares: a propósito de una migrante de la Costa Pacífica en Cali”. In J. Camacho y E. Restrepo (eds), De montes, ríos y ciudades. Territorios e identidades de la gente negra en Colombia. Natura/Ecofondo/Ican, Bogotá, pp.245-262.

QUINTÍN, Pedro (1999b). "Ilustraciones de la Costa Pacífica". In VV.AA, Imágenes de las "culturas negras" del Pacífico colombiano. Documento de Trabajo $\mathrm{n}^{\circ} 40$, CIDSE-IRD, Universidad del Valle, Cali, pp.45-63. 
QUINTÍN, Pedro (2000). Los dramas de los lazos de sangrey de parentesco. Documento de Trabajo $\mathrm{n}^{\circ}$ 51, CIDSE-IRD, Universidad del Valle, Cali, 98p.

RIVAS, Nelly (2000). "Ley 70, medio ambiente y relaciones intra-municipales: El consejo comunitario ACAPA, pacífico nariñense”. In VV.AA., Impactos de la ley 70 y dinámicas políticas locales de las poblaciones afrocolombianas: Estudios de caso. Documento de Trabajo nº 50, CIDSE-IRD, Universidad del Valle, Cali, pp.1-28.

URREA, Fernando. (2000). "Relaciones interraciales y clases en la construcción de ciudadanía: el caso de Cali (Colombia)". InVV.AA. Relaciones interraciales, sociabilidades masculinas juveniles y segregación laboral de la población afrocolombiana en Cali. Documento de Trabajo nº 49, CIDSE-IRD, Universidad del Valle, Cali, pp.2-34.

VANIN, Alfredo (1999). "Alianzas y simbolismos en las rutas de los ausentes". In VV.AA. Imágenes de las "culturas negras" en el Pacífico colombiano. Documento de Trabajo nำ 40, CIDSE-IRD, Universidad del Valle, Cali, pp.3-14.

VERGER, Pierre (1957). Note sur le culte des orisa et vodun. Dakar, IFAN.

WADE, Peter (1993). Blackness and race mixture: the dynamics of racial identity in Colombia. Baltimore, John Hopkins University Press. Edición en castellano: (1997). Gente negra, nación mestiza. Dinámicas de las identidades raciales en Colombia. Editorial Universidad de Antioquia/Instituto Colombiano de Antropología/Siglo del Hombre Editores/ Ediciones UniAndes, Bogotá.

WADE, Peter (1999). "Trabajando con la cultura: grupos de rap e identidad negra en Cali”. In J. Camacho y E. Restrepo (eds), De montes, ríos y ciudades. Territorios e identidades de la gente negra en Colombia. Natura/ICAN/ECOFONDO, Bogotá, pp.263-286.

WHITTEN, Norman (1986[1974]). Black frontiersmen: A South American case. Illinois, Prospect Heights, Waveland Press. 